\title{
Stability Evaluation of a Toppling Deformed Body in Miaowei Hydropower Station
}

\author{
DING Yangbo ${ }^{1}$, ZHANG Faming ${ }^{1}$, YU Zhenghao ${ }^{1}$, and MA Yushan ${ }^{1}$ \\ ${ }^{1}$ School of Earth Science and Engineering, Hohai University, Nanjing 210098, China
}

\begin{abstract}
By analyzing the instability characteristics of deformed body after impoundment and using limit equilibrium algorithm and UDEC discrete element simulation, the failure mechanism and stability of deformed body are studied in the paper. According to the deformation degree and instability characteristics of the deformed body in different storage periods, the mechanism of instability is analyzed. Based on the regional topographic map, a two-dimensional limit equilibrium model is established to calculate the potential failure surface range and slope stability factor of QD18 deformed body under the conditions of $1314 \mathrm{~m}, 1364 \mathrm{~m}$ and $1401 \mathrm{~m}$ water level storage. And the displacement nephogram, velocity nephogram and rock block deformation map of the deformed body under the condition of $1401 \mathrm{~m}$ water level are simulated by using the discrete element software, and the stress changes of each part of the deformed body after water storage are analyzed, and the failure mechanism is summarized.
\end{abstract}

\section{Introduction}

Rocky bedded toppling bank slopes in reservoir area are often destroyed by reservoir water changes during storage or operation period. Under the immersion of reservoir water, the decrease of rock mass and joint mechanical strength is very easy to cause collapse or landslide. Goodman and Bray[1] divided the types of rock slope toppling into block toppling, bending toppling and block-bending toppling according to the deformation mode, and applied the limit equilibrium method to the stability evaluation of anti-dip rock slope. Chen Zuyu[2] improved the Goodman-Bray method considering the connectivity of bottom slip surface and the tensile strength of rock bridge. A large number of scholars at home and abroad have carried out in-depth research[3-7]. There are many toppled and deformed rock masses on the bank slope of Miaowei Reservoir on Lancang River, and after reservoir impoundment, the toppling deformation intensifies, resulting in the collapse of the slope surface. By analyzing the instability characteristics of the toppled deformed rock mass after impoundment, the influence of impoundment on the toppled deformed body and the failure law of the toppled deformed body are summarized.

\section{Characteristics of toppled slopes}

\subsection{Engineering Geological Conditions}

The Miaowei Hydropower Station of Lancang River is located in Yunlong County, Yunnan Province. It is located in a typical high mountain and Canyon landform.
The main strata in the reservoir area are: Jurassic Middle Huakaizuo Formation $\left(\mathrm{J}_{2} \mathrm{~h}\right)$, dark gray, grey-green slate and mudstone; Jurassic Upper Bazhu Formation $\left(\mathrm{J}_{3} \mathrm{~b}\right)$, purple mudstone and slate; Cretaceous Lower Jingxing Formation $\left(\mathrm{K}_{1} \mathrm{j}\right)$, grey-green quartz sandstone and limegreen, purple-red slate, quartz sandstone and mudstone. Layer. The toppling deformation of bank slope rock mass is serious which has a significant impact on the engineering safety of reservoir after impoundment, especially on the right bank transit highway.

\subsection{Srtuctural characteristics of bank slope}

The structural characteristics of anti-dip bank slope in Miaowei reservoir area mainly include two aspects: one is bank slope shape, including slope height and slope angle. The total length of Miaowei reservoir area is about $60 \mathrm{~km}$, and the slope height is over $100 \mathrm{~m}$. Except for loose bank slope, the slope angle is above 30 degrees, and some bank slopes can reach 40 degrees to 60 degrees. The second aspect is the rock structure type and strata occurrence of the bank slope (Fig. 1).

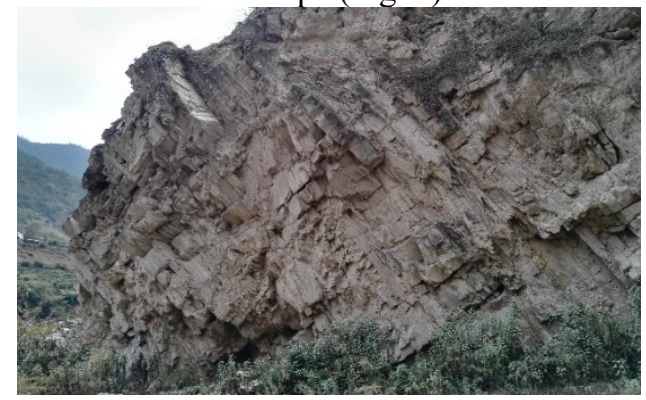

Fig. 1. Structural Characteristics of Bank Slope 
The bank slope of Miaowei reservoir area with toppling deformation bodies is mainly the bank slope of the inverted stratified rock mass and the bank slope of the oblique stratified rock mass, while the bank slope of the downward stratified rock mass has very few toppling deformation bodies.

The dip angle of the bank slope in Miaowei Reservoir is about $70 \sim 85$ degree, which is close to upright, and a group of joints are developed in the rock strata which are nearly vertical to the level. After the toppling deformation of rock strata, with the decrease of the dip angle of rock strata, the joint plane becomes the dominant structural plane out of the slope. The inclination angle of these structural planes is often close to or even larger than the slope angle, which becomes the controlling factor of secondary failure of the toppling deformed body. After reservoir impoundment, on the one hand, the normal stiffness and tangential stiffness of the structure will be greatly reduced, on the other hand, the bank collapse will lead to the loss of the foot of the slope, the upper rock mass of the foot of the slope will lose its support, and the blocks cut by two sets of structural planes and layers are more likely to slide or collapse.

\section{Instability Mechanical Mechanism}

\subsection{Instability Characteristics}

Miaowei Reservoir began to impound in November 2016, and its initial water level was $1314 \mathrm{~m}$. By December 2016, the water level of the reservoir will reach $1364 \mathrm{~m}$; the water level of the reservoir will reach $1401 \mathrm{~m}$ in the third quarter of 2017 and $1408 \mathrm{~m}$ in the third quarter of 2018. The variation of the water level is shown in Fig. 2. When the reservoir is impounded to $1364 \mathrm{~m}, 1401 \mathrm{~m}$ and $1408 \mathrm{~m}$, the toppling bodies in the reservoir area have different degrees of deformation and destruction. Generally speaking, the deformation of the toppled deformation body is related to the bank collapse and the water level depth in front of the slope. The main bank instability occurs at the water depth above $50 \mathrm{~m}$ in front of the slope.



Fig. 2. Water Level Change Process

QD18 toppling deformation is located in $\mathrm{K} 72+800 \sim \mathrm{K} 73+330$ section of transit highway (bank slope number R010). The bank slope is a convex bank with a length of about $0.7 \mathrm{~km}$, a slope direction of about 120 degrees and a slope angle of 31 degrees. In September 2017, when the storage water level was 1401 m, QD18 toppling deformation body collapsed, the direction of the highway extended about $400 \mathrm{~m}$, and the rear edge elevation was about $1520 \mathrm{~m}$. The rear edge of the collapse body is nearly upright, with bedrock exposed and the inner side slope of the highway excavated. It is revealed that the upper overburden layer is mainly Quaternary alluvial-flood drift, pebble layer $\left(\mathrm{Q}^{\mathrm{al}-\mathrm{pl}}\right), 3-5 \mathrm{~m}$ thick, the lower bedrock is strongly weathered sandy slate, and the local metamorphic quartz sandstone is fractured structure.

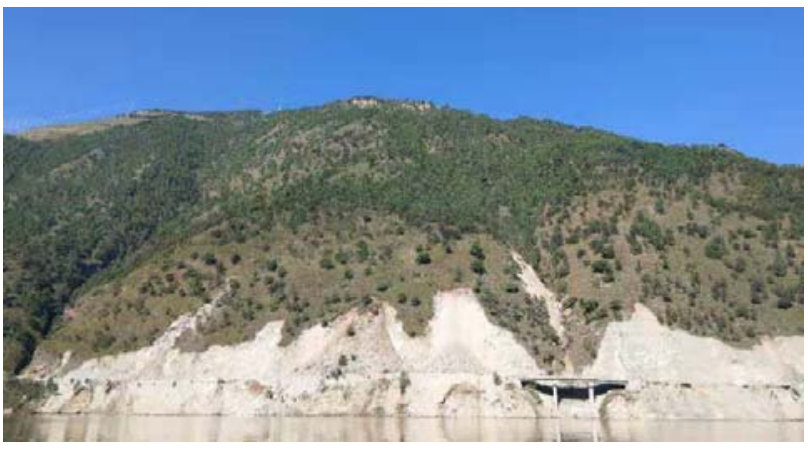

Fig. 3. QD18 Toppling Deformable Body

\subsection{Mechanical Mechanism}

\subsubsection{Compression-shear Failure}

As shown in Fig. 4, the collapse deformed body with compression-shear failure is generally located in the loose Bank of rock mass, which is collapse-buckling type. The rock mass structure is mainly thin layer, layered or fractured structure. Lithology is generally slate, sandy slate. Rock mass quality is poor, weathering is serious, joints are well developed, joint spacing is generally $10-50 \mathrm{~cm}$. The integrality of the toppling deformed body is poor and there is an overhead structure. The failure characteristics are the integral instability of the slope. The slope tends to slide under the pressure of the upper rock mass, which forms a shearing effect on the middle and lower slopes, and ultimately leads to the overall instability failure of the toppled deformed body. After the compression-shear failure, the slope slides downward, and the failure surface is steep and straight, usually more than 60 degrees. The failure surface is relatively smooth and tidy. The failure surface is shovellike, and the lower part is open near the water surface. The failure depth is generally $5-15 \mathrm{~m}$.

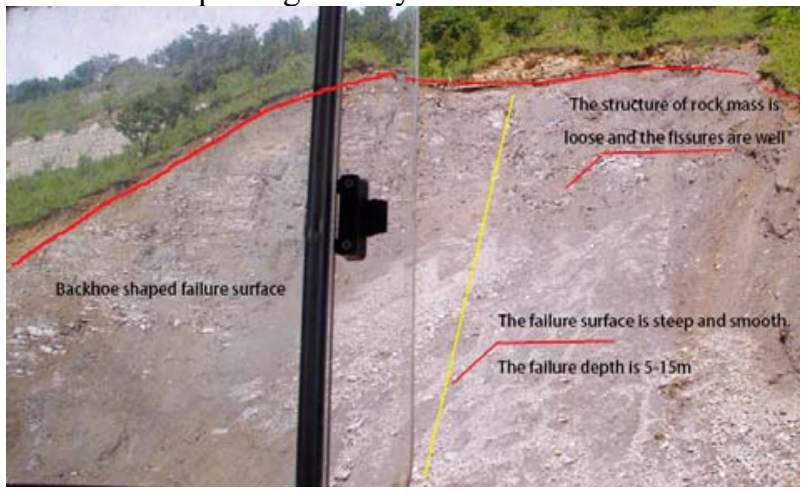

Fig. 4. Compression-shear Failure 


\subsubsection{Tension-shear Failure}

As shown in Fig. 5, the toppling deformed bodies with tension-shear failure are generally located in the shore section with poor rock mass quality. Most of them are toppling loosening or toppling-buckling deformed bodies. Most of the rock mass structures are layered or fractured structures.

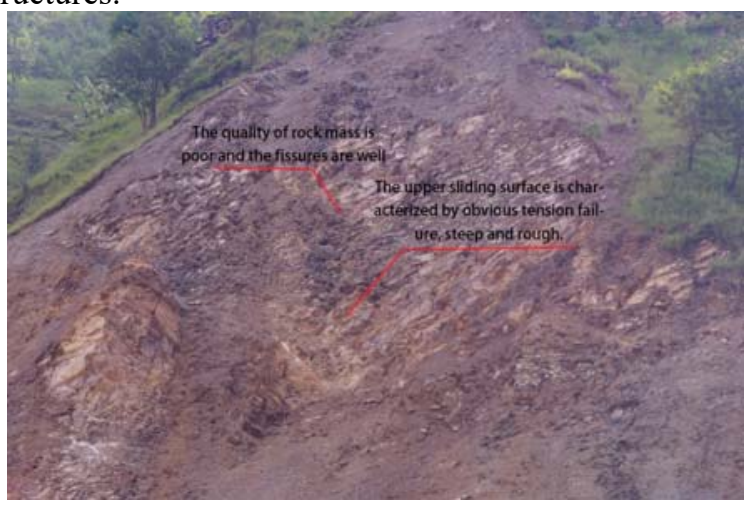

Fig. 5. Tension-shear Failure
Rock mass quality is poor, weathering is serious, joint development, joint spacing is generally $30-80 \mathrm{~cm}$. The failure characteristics are as follows: the whole slope is unstable, and the failure surface is obviously piecewise. The upper part of the failure surface is affected by tension. It is very steep and generally more than 70 degrees. The sliding surface is rough and uneven. The lower part of the failure surface is gently subjected to overall shear action, generally greater than 40 degrees, and the slip surface is relatively flat. The damage depth is usually $5-20 \mathrm{~m}$.

\section{Stability Evaluation of QD18 Toppling Deformation Body}

\subsection{Limit Equilibrium Method}

Select the section 10-10', and the lithology is strong, weak and slightly weathered rock mass from the surface down. The recommended values of geophysical and mechanical indexes are shown in Table 1.

Table 1. Physical and Mechanical Parameters of Rock Mass

\begin{tabular}{|c|c|c|c|c|c|c|c|}
\hline \multirow{2}{*}{ Rock Mass Structure } & \multirow{2}{*}{$\begin{array}{c}\begin{array}{c}\text { Natural } \\
\text { Severe }\end{array} \\
\left(\mathrm{kN} / \mathrm{m}^{3}\right)\end{array}$} & \multirow{2}{*}{$\begin{array}{c}\begin{array}{c}\text { Saturated } \\
\text { Severe }\end{array} \\
\left(\mathrm{kN} / \mathrm{m}^{3}\right)\end{array}$} & \multicolumn{2}{|c|}{$\begin{array}{c}\text { Shear Strength } \\
\text { (Natural) }\end{array}$} & \multicolumn{2}{|c|}{$\begin{array}{c}\text { Shear Strength } \\
\text { (saturation) }\end{array}$} & \multirow{2}{*}{$\begin{array}{r}\begin{array}{c}\text { Tensile } \\
\text { Strength }\end{array} \\
\sigma(\mathrm{MPa})\end{array}$} \\
\hline & & & $\mathbf{c}^{\prime}(\mathbf{M P a})$ & Phi' $\left({ }^{\circ}\right)$ & c'(MPa) & Phi' $\quad\left(^{\circ}\right)$ & \\
\hline Strongly Weathered Sandstone Splint & 21 & 22.5 & 0.11 & 23 & 0.08 & 20 & 1.62 \\
\hline Weakly Weathered Sandstone Splint & 24 & 25 & 0.55 & 31 & 0.4 & 28 & 3.37 \\
\hline Slightly Weathered Sandstone Splint & 26 & 26.5 & 1.2 & 42 & 1 & 39 & 7.22 \\
\hline
\end{tabular}

The section length is $450 \mathrm{~m}$, and the elevation is from $1250 \mathrm{~m}$ to $1621 \mathrm{~m}$. The tension crack at the back edge of the deformed body is located at $1530 \mathrm{~m}$. Under the water level of $1314 \mathrm{~m}, 1364 \mathrm{~m}$ and $1401 \mathrm{~m}$, the slope stability factor is calculated by Bishop method and Morgan StanPrice method (the results are shown in Table 2), and the potential failure surface of the slope is obtained as shown in Figure 6.

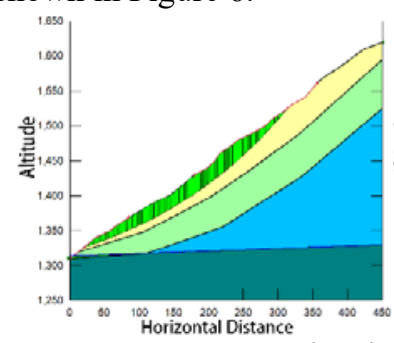

a. $1314 \mathrm{~m}$ Water level

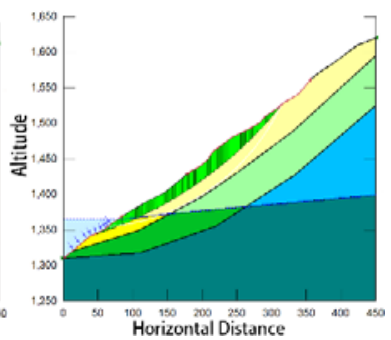

b. $1364 \mathrm{~m}$ Water level



c. $1401 \mathrm{~m}$ Water level

Fig. 6. Potential Failure Surface of Deformed Body under Different Storage Levels
Table 2. Stability Calculation Results

\begin{tabular}{|c|c|c|c|}
\hline $\begin{array}{c}\text { Working } \\
\text { Conditions }\end{array}$ & \multicolumn{2}{|c|}{ Stability Factor/ Fs } & $\begin{array}{c}\text { Shear } \\
\text { Outlet } \\
\text { Position }\end{array}$ \\
\cline { 2 - 3 } & Bishop & $\begin{array}{c}\text { Morgenstern- } \\
\text { Price }\end{array}$ & $1326 \mathrm{~m}$ \\
\hline $1314 \mathrm{~m}$ water level & 1.334 & 1.332 & $1341 \mathrm{~m}$ \\
\hline $1364 \mathrm{~m}$ water level & 1.202 & 1.199 & $1353 \mathrm{~m}$ \\
\hline $1401 \mathrm{~m}$ water level & 0.981 & 0.976 & \\
\hline
\end{tabular}

From Table 2 and Figure 7, it can be seen that the stability coefficient of deformed body before and after impoundment decreases from 1.334 to 1.202 , and becomes 0.981 at $1401 \mathrm{~m}$ water level. At this time, the slope becomes unstable, and the potential shear outlet elevation rises with the increase of impoundment water level. After reservoir immersion, the middle and lower parts of the toppling deformation body are submerged by reservoir water, and the shear resistance of rock and soil becomes weaker. The instability mode of slope foot rock mass changes from toppling to sliding, and the overall slope instability is caused by the loss of the anti-sliding force of the rock mass in the lock-in section at the foot of the slope.

\subsection{Discrete Element Method}

The deformed body discrete element model is shown in Figure 7. The section length is $450 \mathrm{~m}$ and the elevation is from $1250 \mathrm{~m}$ to $1640 \mathrm{~m}$. The deformed body is cut from the rock level and the boundary of the deformed body, and is cut into rigid blocks of different sizes by a group of structural planes in the inclined slope. 


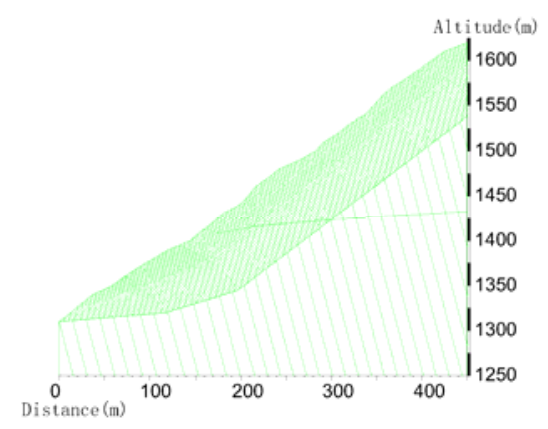

Fig. 7. Discrete Element Model

The total displacement nephogram, velocity vector diagram and block deformation diagram of QD18 bank slope under $1401 \mathrm{~m}$ water storage condition are shown in figs. 8-10.

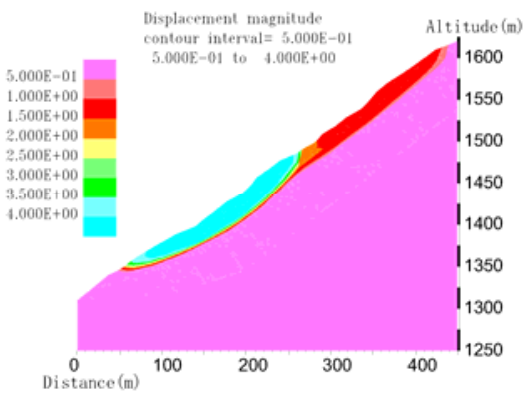

Fig. 8. Displacement Nephogram

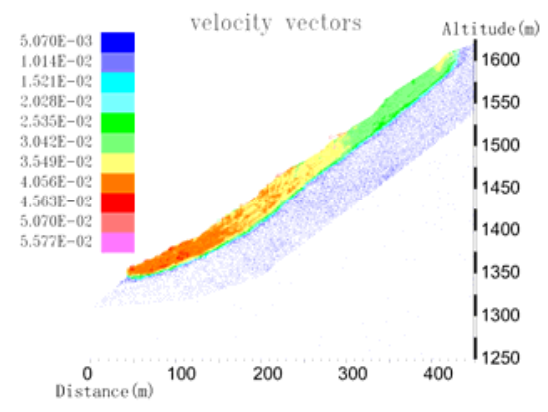

Fig. 9. Velocity Vector Diagram

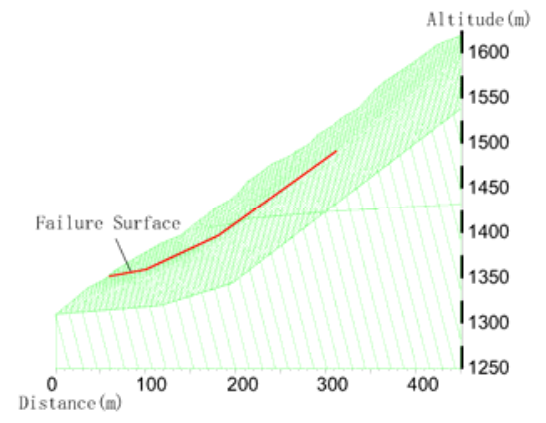

Fig. 10. Block Deformation Diagram

When the water level is $1401 \mathrm{~m}$, there is an obvious displacement differentiation zone in the slope, the maximum displacement is about $3.5 \mathrm{~m}$, the slope has been instable, and the shear outlet is located on the empty surface of the old highway. The rock mass at the foot of the slope is mainly horizontal displacement and the middle and upper parts are deformed vertically. The extrusion deformation of the foot of the slope is serious and the rock mass is destroyed by compression and shear. The inclination angle of the upper rock mass is very small and the deformation is obvious. The compressionshear failure occurs after the QD18 deformation body is impounded.

\section{Summary}

(1) The instability mechanics mechanism of toppling deformed body in Miaowei reservoir area after impoundment is divided into tension-shear failure and compression-shear failure.

(2) According to the limit equilibrium algorithm, the stability coefficients of QD18 toppled deformed bodies are $1.334,1.202$ and 0.981 respectively at storage water levels of $1314 \mathrm{~m}, 1364 \mathrm{~m}$ and $1401 \mathrm{~m}$. When the water impoundment reaches $1401 \mathrm{~m}$, the slope loses its antisliding force due to the softening of the foot of the slope by the reservoir water.

(3) According to the discrete element method (DEM) simulation, the shear resistance of saturated rock and soil becomes weaker after impoundment, the instability mode of slope foot rock mass changes from toppling to sliding, and the overall instability of slope foot lock section rock mass is caused by the loss of anti-sliding force on the upper rock mass.

\section{References}

1. GOODMAN R E.BRAY J W. Topploing of Rock Slopes[C]// ASCE. Proceedings of the Specialty Conference on Rock Engineering for Foundations and Slopes. Reston: ASCE,1976:201-234.

2. Chen Zuyu, Cai Yunpeng, Wang Yujie, et al. Improvement, Testing and Application on Goodmam-Bray Method for Stability Analysis of Toppling Slope[J]. China Journal of Highway and Transport, 2018, 31 (02): 30-38.

3. Zheng Yun, Chen Congxin, Liu Xiumin, et al.Investigation on Calculation Method of Layered Counter-tilt Slope for Flexural Toppling Failure [J]. Chinese Journal of Rock Mechanics and Engineering, 2015, 34 (S2): 4252-4261.

4. Luo X, Tao C, Xin L, et al. Slope safety factor search strategy for multiple sample points for reliability analysis[J]. Engineering Geology, 2012, 129-130(2):27-37.

5. Dunand M, Mohr D. On the predictive capabilities of the shear modified Gurson and the modified Mohr-Coulomb fracture models over a wide range of stress triaxialities and Lode angles[J]. Journal of the Mechanics \& Physics of Solids, 2011, 59(7):1374-1394.

6. Scholtes L_ Donze F V. A DEM analysis of steppath failure in jointed rock slopes [J]. Comptes Rendus Mecanique, 2015, 343(2): 155 - 165.

7. Bowles J E. Foundation analysis and design[M]. McGraw-Hill, 1988:269. 